process, and built-in analytics are used to monitor and improve services provided.

Conclusion Carefully-designed online communities of practise can bring practitioners together to learn and share across geographic boundaries and without incurring the costs of face-to-face meetings. They are consonant with adult learning and professional development strategies that underscore the importance of participation not only in initial training events, but also the value of ongoing coaching, technical assistance, and peer network support.

\section{P5.050 STD PREVENTION ONLINE: A NETWORKING WEBSITE FOR STD/STI PROFESSIONALS}

doi:10.1136/sextrans-2013-051184.1094

1,2C A Rietmeijer. 'Colorado School of Public Health, Denver, CO, United States, ${ }^{2}$ American Sexually Transmitted Diseases Association, Research Triangle Park, NC, United States

Background STDPreventionOnline. Org (STDPO) is an online professional networking web site for the sexually transmitted diseases/infections (STD/STI) work force, including researchers, clinicians, epidemiologists, disease intervention specialists, and programme managers. The site was developed by the Internet and STD Center of Excellence, originally funded by a grant from the U.S. Centers for Disease Control and Prevention and currently sponsored by the American Sexually Transmitted Diseases Association. The site was a conceived as a two-way clearing house of current STD/STI information and resources, where members can both download and upload information in a variety of formats, including text, graphics, audio/video formats as well as post blog and forum entries. Membership to the website (www.stdpreventiononline. org) is free.

Objective To describe current users and usage of STDPO.

Methods Descriptive statistics were obtained from embedded website metrics and Google Analytics $@$.

Results Since its inception in 2007, the site has registered 3,587 users; the site's monthly newsletter has over 4,100 subscribers. The predominance of members ( $92 \%$ ) live/work in the United States; however a substantial number (387 as of February 2013), are non-US users with 52 countries represented. Most members (58\%) work in STD/STI programmes in state/local health departments, $13 \%$ in community or private clinics, $11 \%$ in a university setting, $8 \%$ in federal government, and $8 \%$ in community organisations. During 2012, the site logged 8,240 site visits and 32,462, respectively 158 and 624 per week. To date 1,142 resources have been uploaded to the site which were downloaded 44,517 times, an average of 39 downloads per resource. Topics related to Internet use and online interventions are particularly popular, followed by clinical slide sets and podcasts. Conclusion During the 5 years of its existence, STPDO has demonstrated to meet a need in the STD/STI professional community for an interactive, two-way, clearing house of STD/STI-related information.

\section{P5.051 "THERE ARE A MILLION SCENARIOS TO CONSIDER": HEALTH CARE PROVIDER PERSPECTIVES ON INTERNET- BASED TESTING FOR SEXUALLY TRANSMITTED INFECTIONS, HIV, AND HEPATITIS C IN BRITISH COLUMBIA}

doi:10.1136/sextrans-2013-051184.1095

\begin{abstract}
${ }^{1,2}$ M Gilbert, 'T Salway Hottes, ${ }^{2} \mathrm{C}$ Chabot, 'D Haag, ${ }^{2} \mathrm{~J}$ Shoveller, ${ }^{1,2} \mathrm{G}$ Ogilvie. 'British Columbia Centre for Disease Control, Vancouver, BC, Canada; ${ }^{2}$ School of Population and Public Health, University of British Columbia, Vancouver, BC, Canada
\end{abstract}

Background Online health interventions are integrated within existing systems of sexual health care, however, their perception by health care providers is rarely considered. We sought to understand the opinions of health care providers working in sexual and reproductive health of GetCheckedOnline (GCO), a new internet testing programme for STIs, HIV and Hepatitis C in British Columbia, and how they perceived it integrating with their future practise.

Methods In 2012, one investigator conducted six focus groups with a total of 49 participants (21 nurses, 12 physicians, 16 other staff); observers in each group took notes, supplemented by audio recordings where possible. Participants were presented with the GCO model and questioned about perceived risks, benefits, utility, and impact on/integration with their practise. Focus group notes were thematically analysed using NVivo and findings validated with observers.

Results Focus group participants described GCO as an inevitable evolution within and complement to the current system of care, where the benefits of shifting locus of control to patients, addressing testing barriers, and increasing engagement in care may be offset by perpetuating existing inequities for some groups. Participants discussed the potential for personal harm (e.g., anxiety at receipt of positive results, misunderstanding of limitations of tests) and clinical harm related to provision of inadequate/sub-standard clinical care. However, they also indicated that they were likely to integrate GCO with their own practise, under certain scenarios (e.g., referral of low-risk clients or triage of people seeking testing appointments).

Conclusions Providers expressed favourable opinions of internet testing in general and support for GCO. Concerns about potential harms (many of which participants acknowledged existed within the current clinic-based testing system) were generally offset by the perceived benefits of the service. Participants also provided many suggestions for mitigation of potential harms, which have been incorporated into the GCO programme where possible.

\section{P5.052 KNOWLEDGE AND AWARENESS OF CERVICAL CANCER, HUMAN PAPILLOMAVIRUS (HPV) AND HPV VACCINES AMONG MEDICAL STUDENTS}

doi:10.1136/sextrans-2013-051184.1096

'V C Sangar, ${ }^{2} \mathrm{~B} B$ Ghongane, ${ }^{3} \mathrm{~S} S$ Rajdherkar. 'Byramjee Jeejeebhoy Medical College, Pune, India; ${ }^{2}$ Government Medical College Miraj, Miraj, India; ${ }^{3}$ Maharashtra University of Health Sciences, Nashik, India

Background Cervical cancer is one of the leading causes of morbidity and mortality among the gynaecological cancer worldwide. Therefore, medical students in developing countries like INDIA should have sound knowledge about this disease. In this study we aim to access the current knowledge amongst medical students about cervical cancer, HPV and HPV vaccines.

Methods A cross-sectional, questionnaire based survey was conducted among 355 medical students during October 2012 to Jan 2013 in the tertiary medical care hospital. Out of 355 medical students, 129 students $(36.33 \%)$ were from preclinical stage (I MBBS) belongs to group I, 148 students (41.69\%) from paraclinical stage (II $\mathrm{MBBS}$ ) belongs to group II and 78 students were from clinical stage belongs to group III (III MBBS onwards).

Results Out of 355 medical students, 326 participants (91.83\%) were aware that virus is the causative agent of cervical cancer. The 218 participants $(61.4 \%)$ knew about the route of cervical cancer transmission. The most common risk factor reported by 185 (52.11\%) participants was poor hygiene. The 66 participant reported most common presenting feature was bleeding per vaginal (18.59\%). The results showed that 263 students $(74.08 \%)$ were unaware about the proper route of HPV vaccine administration. They are also unaware about HPV vaccines availability, vaccine dosing schedule, target age group, manufacturers and vaccine preparation technology. 